IRA-International Journal of Management \& Social Sciences

ISSN 2455-2267; Vol.04, Issue 02 (2016)

Pg. no. 483-493

Institute of Research Advances

http://research-advances.org/index.php/RAJMSS

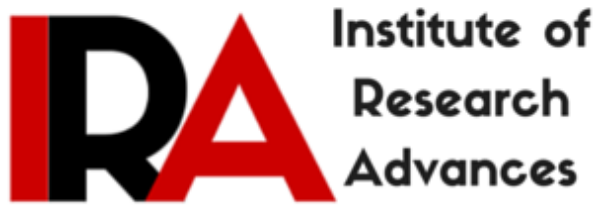

\title{
The Determinants of Economic Growth in CEMAC through a Panel Data Approach
}

\author{
Nzingoula Gildas Crepin \\ Economist \& Statistician \\ African Union Commission, Economic Affairs Department \\ Addis Ababa, Ethiopia.
}

Type of Review: Peer Reviewed.

DOI: http://dx.doi.org/10.21013/jmss.v4.n2.p19

\section{How to cite this paper:}

Crepin, N. (2016). The Determinants of Economic Growth in CEMAC through a Panel Data Approach. IRA-International Journal of Management \& Social Sciences (ISSN 2455-2267), 4(2), 483-493. doi:http://dx.doi.org/10.21013/jmss.v4.n2.p19

(C) Institute of Research Advances

\section{(c) EY-NO}

This work is licensed under a Creative Commons Attribution-Non Commercial 4.0 International License subject to proper citation to the publication source of the work.

Disclaimer: The scholarly papers as reviewed and published by the Institute of Research Advances (IRA) are the views and opinions of their respective authors and are not the views or opinions of the IRA. The IRA disclaims of any harm or loss caused due to the published content to any party. 


\begin{abstract}
This article highlights through a panel data approach the determinants of economic growth; observed over the last decade in the Economic and Monetary Community of Central Africa (CEMAC) and necessary to reach emerging economies stage. To do this, we essentially used Stata 12 software to come up with the results, and a panel data sample comprising six CEMAC member states, namely Congo, Cameroon, Gabon, Equatorial Guinea, Central African Republic and Chad, for the period ranging from 2000 to 2013. The results obtained after estimating ordinary least squares, fixed effects model, random effects model, generalized method of moments (GMM) and specification tests show that the best model to estimate these types of data is the fixed effects model. Besides, the main determinants of economic growth in CEMAC over that period are Foreign Direct Investment (FDI) and loans lending to the economy (LOAN). After estimation, FDI is found positive and significant on economic growth, while LOAN is significant and found negative maybe due to lack of good governance.
\end{abstract}

Keywords : economic growth ; emerging economies; CEMAC; panel data; fixed effects model; random effects model; OLS; GMM.

\title{
I. Introduction
}

Over the past decade, many developing countries expressed their aspirations and developed their business plan in order to reach the emerging economies stage. Among those countries some are in Africa. In Central Africa, particularly countries from Economic and Monetary have set up goals, namely becoming emerging economy. In this regard, five of the six countries from CEMAC have already stated quantify targets. Among those countries, we have Cameroon formally expressed its ambitions and declared to be emerging economy in 2035, Chad in 2030, Congo and Gabon in 2025, and Equatorial Guinea in 2020. Only Central African Republic facing political instability and struggling to cope with the adverse effects of the recent civil war has not officially expressed objectives in view of the emerging economy.

However, as you aware CEMAC member countries want to follow the path leading to emerging economy. To achieve that, they have to get an acceptable level of a economic growth rate and sustainable over time and space because only such sustainable economic growth rate could enable them to reach the stage of emerging economies compared to the deadlines they have assigned themselves. But, achieving those levels of economic growth accompanied by an improvement in social indicators and well-being of their citizens requires to know its determinants in order to sustain it over time, and implement relevant economic and social policies enabling them being emerging economies. Indeed, CEMAC, which overflow with many natural resources, transforming these assets into wealth benefiting its citizens, the identification of determinants is crucial for the choice of type of economic and social policies to apply leading to the stage of emerging economies.

According to the 2013 statistics, CEMAC's assets are as follows: population (estimate): 46,572,000; growth (real GDP): 4.08; population growth rate (average): 2.8 ; real growth rate: $1.3 \%$; inflation: $2 \%$. With natural resources underutilized, the economy of the CEMAC member states remains very poorly diversified, private sector and technology areas undeveloped; knowing these key economic growth drivers is becoming crucial.

Economic growth is defined as a sustained increase during one or more long periods (one year) of the Gross Domestic Product (GDP) in real terms. There are two forms of economic growth: extensive economic growth proportional to the increase in the quantity of production factors, and intensive economic growth which is linked to the used of labor and capital increasing productivity. In short, economic growth of a country is inexorably linked to its productive capacity.

In this regards, the current study aims to find out the determinants of economic growth in CEMAC. It will help us to identify the variables on which policy or decision makers should emphasize to generate strong and sustainable economic growth necessary for CEMAC member states to be emerging economies in the long run. 


\section{Literature review}

Despite the absence of a unifying theory, there are several partial theories that discuss the role of different determinants of economic growth. Two main have emerged from these theories: neoclassical and endogenous growth models. Neoclassicism is based on the Robert Solow growth model built from a critical reflection based on the Harrod-Domar's model. The Solow model emphasizes the importance of capital accumulation, the increase in the workforce and the ability to innovate as determining factors in the process of growth. More recently, the endogenous growth theory developed by Romer and Lucas has drawn attention to human capital and innovation capacity. These recent growth theories reject the Solow model in favor of an endogenous growth model that assumes constant returns and assumes the capital increase with time.

Over the past two decades, significant contributions to economic growth were made. The implementation review of these empirical studies allowed us to identify some that highlight the key factors that influence economic growth. From these studies, we can note:

The study by Barro (1991) on a sample of 98 countries for the period 1960 to 1985, concluded that the real growth rate per capita growth is positively related to human capital;

The study by Fisher (1993) showed that a part of macroeconomic policy for growth is a necessity. It is clear from this analysis that there is a broad consensus that the long-term growth is negatively associated with inflation and positively correlated with good financial performance and exchange markets (see Fischer 1993);

The study of Levine and Zervos (1993) shows countries that have more students enrolled in secondary schools grow faster than countries with enrollment in lower secondary education. Brunetti and al. (1998) noted that education, as measured by the secondary enrollment rate is positively related to growth. Martin and Xavier (1997) also confirm that the various educational related positively to growth.

Brunetti andal. (1998) claim that two channels through which policies can influence economic growth are efficiency and reliability. Efficiency reflects the implementation of macroeconomic and microeconomic policies in a timely manner; while reliable conditions refer to the stability around their implementation.

It is generally accepted that political instability has a negative impact on growth and that countries that have more revolutions and coups are growing more slowly than most politically stable countries. These views are strongly supported by Levine and Zervos (1993) and conclude that political instability is a statistically significant deterrent to economic growth.

The fifth factor that has a major impact on economic growth is inflation. Policy makers generally believe that inflation has significant negative long-term effects on economic performance (Clark, 1993). The reason for this, as noted by Fischer and Modigliani (1978) is that businesses and workers spend productive resources to deal with inflation.

According to Levine and Zervos (1993), new research suggests that economies with more developed and efficient financial systems will be able to more effectively allocate resources to the best investments, which in turn lead to an increase in productivity, higher savings rates, and rapid economic growth.

Trade Openness has been widely used in the literature of economic growth as a major determinant of growth performance. There are strong theoretical reasons to believe that there is a strong positive link between openness and growth. The opening affects economic growth through various channels such as the exploitation of comparative advantage, technology transfer and dissemination of knowledge, increased economies of scale and exposure to competition. Much of the literature revealed that the economies that are more open to trade and capital flows have a GDP per capita higher and increased faster (Dollar 1992, Sachs and Warner, 1995 Edwards 1998 Dollar and Kraay, 2000).

The Foreign Direct Investment (FDI) has recently played a key role in the internationalization of economic activity and is the main source of technology transfer and economic growth. This important role is emphasized in several models of endogenous growth theory. The empirical literature examining the impact of FDI on growth has provided more or less consistent findings affirming a 
positive and significant relationship between the two (eg Borensztein andal, 1998; and Hermes Lensink).

Armstrong and Read (2004) stating that natural resources, climate, topography and "encirclement" has a direct impact on economic growth affecting productivity, economic structure, transportation costs and competitiveness.

\section{Data sources}

The data sources used in the framework of our estimates are mainly from the Bank of Central African States (BEAC) and the World Development Indicators (WDI 2014). From these data sources, we have built a panel dataset comprising 6 countries, namely all CEMAC member states. The panel constituted may be considered an annually cylinder Panel data covering the period from 2000 to 2013, with 84 observations. The choice of this period is justified by the availability of data and the relative stability of the latter. The six CEMAC member states in the dataset are: Congo, Cameroon, Gabon, Equatorial Guinea, Central African Republic and Chad.

\section{Research methodology}

The choice of panel model is justified by the fact that data used in this article requires panel data techniques and this model has several advantages, such as its ability to take into account the heterogeneity of each country, influence of unobservable characteristics and multicollinearity among the variables. To identify macroeconomic variables or models that may explain and leverage economic growth observed in CEMAC member states, we have step up and estimated 4 econometric models. The construction of these models and the identification of the most suitable model among these 4 were done according the following steps:

- Firstly: Fisher, Hausmann and Breusch-Pagan tests are being used to determine the suitable econometric modelling with regard to the dataset selected;

- Secondly: We have four econometric models formulated from the literature review. Among these estimated models, we have: ordinary least squares (OLS), fixed effects model (FEM), random effects model (REM) and generalized method of moments (GMM);

- Thirdly: Although the specification tests converge to the conclusion that the suitable model for the modelling of the dataset is FEM, and for the consistency and reliability of the results after the modelling, we did normality test on residuals to identify with confidence the best model among the four aforementioned.

\section{a) Macroeconomic aggregates and model form}

After analyzing the literature review in order to identify variables needed to be included in our model, we selected a sample of variables may influence and have a significant impact on economic growth in the CEMAC member states. The theoretical model specification derived from the literature review; as acronyms of the variables we have:

\begin{tabular}{|l|l|}
\hline acronyms & Detail names of the acronym variables \\
\hline GDP & $\begin{array}{l}\text { Gross Domestic Product rate uses a proxy to measure economic } \\
\text { growth }\end{array}$ \\
\hline TO & Trade Openness \\
\hline DEBT & $\begin{array}{l}\text { Payments due under debt contracts. This includes payment of } \\
\text { interests as it becomes due, and redemption payments }\end{array}$ \\
\hline LOAN & $\begin{array}{l}\text { Amount of money borrowed, often from a bank, and has to be } \\
\text { paid back usually together with an extra amount of money }\end{array}$ \\
\hline FDI & Foreign Direct Investment \\
\hline HC & Human Capital \\
\hline INF & Inflation \\
\hline landlock & takes a value 1 if the country Is landlock and 0 otherwise \\
\hline
\end{tabular}


The model as a linear combination of the variables may be presented in the following general form:

$$
G D P=f(T O, D E B T, L O A N, F D I, I N F, H C, \text { landlock })
$$

By taking in its linear form, the model can be written in equation form as:

$$
\begin{gathered}
G D P_{i t}=\alpha_{i}+\beta_{0}+\beta_{1} F D I_{i t}+\beta_{2} I N F_{i t}+\beta_{3} D E B T_{i t}+\beta_{4} L O A N_{i t}+\beta_{5} H C_{i t}+\beta_{6} T O_{i t} \\
+\beta_{7} \text { landlock }_{i t}+\varepsilon_{i t}
\end{gathered}
$$

Where :

$i:$ a given country

$\alpha_{i}$ : specific effect or individual effect;

$t$ : time period ranging from 2000 à 2013 ;

$\beta_{i}, i=0,1,2, \ldots, 7$ parameters;

$\varepsilon_{i t}$ : Error term, $E\left(\varepsilon_{i t}\right)=0 \forall i, t$

\section{b) Specification tests}

We have used the specification tests in order to choose the suitable econometric model. In this regard, these specification tests enable to determine which of the 4 models (OLS, fixed effects model, random effects model and GMM) is best suited in comparison to our data.

\section{i) Fisher test}

The Fisher test is used to arbitrate between the specific effect (existence of specific characteristics for each country) and the overall effect (lack of specific characteristics for each country). The test principle is:

$$
\left\{\begin{array}{l}
H_{0}: \text { total homogeneity of the parameters } \\
H_{1}: \text { partial homogeneity of the parameters }
\end{array}\right.
$$

We accept $H_{0}$ if $F^{c}<F_{(n-1, n k-n-k)}^{\alpha}=\frac{\left(S S R_{L S D V}-S S R_{p o o l e d}\right) /(N-1)}{S S R_{L S D V} /(N *(T-1)-K)}$

Fisher's exact test result obtained after removing landlock variable due to collinearity, gives us

$$
F(5,72)=3,8 \quad \text { Prob }>F=0,0041 \text { at the threshold } 5 \%
$$

According to the test results $(p-$ value $=0,0041<0,05)$, we can reject the null hypothesis and accept existing of individual effects. As you know, individual effects are two types: fixed effects and random effects. This result should be deepened through the Hausman test to find out which model is suitable.

\section{ii) Hausman test}

The Hausman test (1987) can be applied to many econometric problems requires specification. In our case, the tested hypothesis provides guidance accepted way of choosing between fixed and random effects.

We test $\left\{\begin{array}{l}H_{0}: \text { the adequate model is random effects model } \\ H_{1}: \text { the adequate model is fixed effects model }\end{array}\right.$

Hausman's specification test applied as follows:

$$
H=\left(\hat{\beta}_{M E F}-\hat{\beta}_{M E A}\right)^{\prime}\left[\operatorname{Var}\left(\hat{\beta}_{M E F}-\hat{\beta}_{M E A}\right)\right]^{-1}\left(\hat{\beta}_{M E F}-\hat{\beta}_{M E A}\right) \sim X_{\alpha}^{2} \text { sous } H_{0}
$$

The results are: $\operatorname{chi2}(8)=(b-B)^{\prime}\left[\left(V_{b}-V_{B}\right)^{-1}\right](b-B)=18,4$ and Prob $>$ chi2 $=0,0053$

The result from the Hausman test led to reject the null hypothesis and accept the alternative hypothesis about existing of fixed effects. The model used is therefore the fixed effects model. However, ensuring the consistency and robustness of these results, we will use the Breusch-Pagan test 
to choose definitively on the type of model that can be used for estimating the determinants of economic growth in CEMAC.

\section{c) Breusch Pagan test}

Under its null hypothesis $\mathrm{H}_{0}$, the Breusch Pagan test may enable to choose whether the OLS estimation of the pooled model is adequate against the random effects model.

$$
\left\{\begin{array}{l}
H_{0}: \quad y_{i t}=\alpha+\beta^{\prime} x_{i t}+\varepsilon_{i t} \quad \text { No random effects } \\
H_{1}: \quad y_{i t}=\alpha+\beta^{\prime} x_{i t}+\alpha_{i}+\varepsilon_{i t} \text { Yes random effects }
\end{array}\right.
$$

The Breusch- Pagan estimator is: $L M=\frac{n T}{2(T-1)}\left[\frac{\sum_{i}\left(\sum_{t} \hat{e}_{i t}\right)^{2}}{\sum_{i} \sum_{t} e_{i t}^{2}}-1\right]^{2} \sim X_{(1)}^{2} \quad$ under $H_{0}$

The calculated p-value is greater than $5 \%$, this allows us to conclude that the OLS model is more appropriate than the random effects model. In short, the Breuch-Pagan test led to validate the OLS model.

Table 1 : Summary on the specification tests

Source : author

\begin{tabular}{|l|l|l|l|}
\hline Type of the tests & p-value & Hypothesis $H_{0} / H_{1}$ & Choice \\
\hline Fisher & 0.0166 & OLS / FEM & MEF \\
\hline Breusch-Pagan & 1.00 & OLS / REM & OLS \\
\hline Hausman & 0.6911 & REM / FEM & FEM \\
\hline
\end{tabular}

The summary table on the specification tests above informs us that among the three models (OLS, FEM, REM ${ }^{1}$ ), the best model to estimate the determinants of economic growth in CEMAC is the fixed effects model. Although, there are differences and specificities among CEMAC member states, and in order to confirm these claims, we will deepen our analysis by estimating GMM. Then, the results of this estimate and the Jarque-Bera normality test will allow us to decide accurately on the nature of the model being adopted.

\section{Forms and specification of the OLS, FEM, REM and GMM models}

This section presents the equation forms of the different models proposed to determine the factors influencing economic growth in CEMAC, because decision makers and Governments need to know factors having impact on any economic policies leading to a sustainable economic growth and the stage of emerging economies.

\section{a) Fixed Effects model}

The fixed effects model is known as LSDV (Least Squares Dummy Variables). In developing this model, we assume that the relationship between the dependent and independent variables are the same for all countries. In our case, we have 6 African countries observed over 14 years and 7 variables.

Taking into account the specificities of each country, we have used dichotomous variables.

Where: pcam $=1$ if the observation belongs to Cameroon and 0 otherwise, $p r c a=1$ if the case belongs to Central African Republic and 0 otherwise, and so on. Given there are 6 countries, and to avoid any collinearity, only 5 of the 6 dichotomous variables will be used, namely the following dichotomous variables: pcam, pcong, ptch, pgab et pguin

Adopting this pattern, the present study specifies the following equation form :

$$
\begin{gathered}
G D P_{i t}=\alpha_{i}+\beta_{1} F D I_{i t}+\beta_{2} I N F_{i t}+\beta_{3} D E B T_{i t}+\beta_{4} L O A N_{i t}+\beta_{5} H C_{i t}+\beta_{6} T O_{i t}+\beta_{7} \text { landlock }_{i t} \\
+\varepsilon_{i t}
\end{gathered}
$$

\footnotetext{
${ }^{1}$ OLS : Ordinary Least Squares

FEM : Fixed Effects Model

REM: Random Effects Model
} 


\section{b) Random effects model}

The random effects model admits that the individual specificity is each country, i.e, the constant term for each country is random. It breaks down into a fixed term and a random term. It assumes that each country has its own random perturbation, which is constant in time. Moreover, the coefficient of any explanatory variable in the model is the same for all countries. The model to estimate is the following form:

$$
\begin{gathered}
G D P_{i t}=\alpha_{0}+\beta_{1} F D I_{i t}+\beta_{2} I N F_{i t}+\beta_{3} D E B T_{i t}+\beta_{4} L O A N_{i t}+\beta_{5} H C_{i t}+\beta_{6} T O_{i t}+\beta_{7} \text { landlock }_{i t} \\
+\varepsilon_{i t}+\mu_{i}
\end{gathered}
$$

$\mu_{i}$ random effet of the country $i$, and for $\varepsilon_{i t}+\mu_{i}=\vartheta_{i t}$ the model is as follows :

$G D P_{i t}=\alpha_{0}+\beta_{1} F D I_{i t}+\beta_{2} I N F_{i t}+\beta_{3} D E B T_{i t}+\beta_{4} L O A N_{i t}+\beta_{5} H C_{i t}+\beta_{6} T O_{i t}+\beta_{7}$ landlock $_{i t}+$ $\vartheta_{i, t}$ with $\vartheta_{i t}$ as a composite error term

\section{c) Ordinary least squares on Pooled data}

In the case of OLS model, we adopt the hypothesis that all coefficients are constant during the study period ranging from 2000 to 2013 , and the coefficients got after estimation are statistically the same for all countries. In other words, this model assumes countries of the CEMAC are homogeneous. This model can be written in equation form as:

$$
\begin{gathered}
T G D P_{i t}=\alpha+\beta_{1} F D I_{i t}+\beta_{2} I N F_{i t}+\beta_{3} D E B T_{i t}+\beta_{4} L O A N_{i t}+\beta_{5} H C_{i t}+\beta_{6} T O_{i t}+\beta_{7} \text { landlock }_{i t} \\
+\varepsilon_{i t}
\end{gathered}
$$

\section{d) Generalized Method of Moments (GMM) model}

Non convergence observed in the findings we arrived after analyzing the results of Fisher, Hausmann and Breusch-Pagan tests might suggest the existence of bias in some of the estimated models. Besides, these biases could also be caused by measurement errors, omissions of the variables and reverse causality. The method specified for type of these problems is the Generalized Method of Moments (GMM), developed for the first time by Holtz-Eakin, Newey and Rosen in 1988 and improved by Arellano and Bond in 1991, by Arellano and Bover in 1995 and then by Blundell and Bond in 1998.

The dynamic model is written as follows:

$$
\begin{gathered}
G D P_{i, t}=\alpha_{0}+\alpha_{i}+\varphi G D P_{i, t-1}+\beta_{1} F D I_{i t}+\beta_{2} I N F_{i t}+\beta_{3} D E B T_{i t}+\beta_{4} L O A N_{i t}+\beta_{5} H C_{i t}+\beta_{6} T O_{i t} \\
+\beta_{7} \text { landlock }_{i t}+\varepsilon_{i t}
\end{gathered}
$$

Where: $\varphi$ et $\beta_{k}, k=1, \ldots, 9$ are parameters and $\alpha_{i}$ fixed effects at country level.

\section{Normality Test for residuals}

The normality test applied to residuals generated after the model estimation of the Generalized Method of Moments and fixed effects is Jarque-Bera test. This test aims to determine whether the residuals behave a normal distribution or not.

The test principle is:

$$
\left\{\begin{array}{l}
H_{0}: \text { residual distribution behaves as a normal distribution } \\
H_{1}: \text { residual distribution does not behave as a normal distribution }
\end{array}\right.
$$


Table 2 : Normality Test result on residuals of the GMM model

\begin{tabular}{|r|ccccc|}
\hline \multicolumn{7}{r|}{ Variable } & Obs & $\operatorname{Pr}$ (Skewness) & $\operatorname{Pr}$ (Kurtosis) & adj chi2 (2) & Prob>chi2 \\
\hline residu_GMM & 78 & 0.0013 & 0.0093 & 13.83 & 0.0010 \\
\hline
\end{tabular}

Source: author

The probability of the normality test is $p-$ value $=0,001<0,05$, this allows us to reject the null hypothesis $H_{0}$ and conclude the residuals generated after estimating the GMM are not normally distributed.

Table 3 : Normality Test result on residuals of the fixed effects model

\begin{tabular}{|r|ccccc|}
\hline \multicolumn{7}{r}{ Variable } & Obs & $\operatorname{Pr}$ (Skewness) & $\operatorname{Pr}$ (Kurtosis) & adj chi2(2) & Prob>chi2 \\
\hline residu_fixe & 84 & 0.1276 & 0.5182 & 2.83 & 0.2430 \\
\hline
\end{tabular}

Source: author

The probability of normality test gives a $p-$ value $=0,243>0,05$, this allows us to accept the null hypothesis of normality $\left(H_{0}\right)$ and conclude the residuals generated after estimating the fixed effects model behave as a normal distribution.

Following the results of the various tests and estimates, the best model among the four stated above to better identify the determinants of economic growth in the countries of the CEMAC is the fixed effects model.

\section{Results and discussions}

The regression of the growth rate of Gross Domestic Product per capita (GDP) on macroeconomic variables (FDI, INF, DEBT, LOAN, TO, HC and landlock), identified by the literature review as likely to influence economic growth, has been made through the OLS, FEM, REM and GMM models. Different tests carried out have allowed us to conclude that the fixed effects model is the best model with regard to the structure of our data and the results of these regressions are summarized in the table below.

At first glance, we see from the summary table there are variables that are statistically significant, but have either positive or negative impact on GDP, and other variables are not significant at all.

According to the GMM estimation, $G D P_{t-1}$ variable (t-1) is correlated positively and significantly with the dependent variable $G D P_{t}$. In economic terms, the current GDP $(t)$ depends on the previous year $(t-1)$.

It also emerges from the analysis of the table that 2 of the 7 variables stand out from others, namely foreign Direct Investment (FDI) and loans to the economy (LOAN). These two variables have a significant impact on economic growth of the CEMAC member states. However, if FDI has a positive impact on economic growth of these economies, loan has negative impact. FDI appears as the only variable having a positive and significant impact on economic growth in all the countries of the CEMAC. This tend confirms some results obtained by the theorists of endogenous growth (Lucas 1988, Romer, 1990), relating to the positive role of investment on economic growth.

The negative effect of credit on the economy could be explained by the fact that these loans were used to finance unproductive projects in terms of contribution to economic growth or they were diverted from their original purpose, which raises the issue of good governance in the CEMAC. Indeed, Rajkumar and Swaroop (2002) demonstrated from a comparative analysis based on panel data for the period from 1990 to 1997, that good governance (measured by the degree of corruption and 
bureaucratic quality) has a positive impact on the effectiveness of public spending in stimulating economic growth.

The impact of the debt is negative in some countries of the CEMAC, this could be explained by the fact that interest payments on public debt are relatively high, meaning part of the amount listed for expenses investment may affect economic growth. Consequently, it appears that the debt has a negative effect on economic growth in CEMAC.

Human Capital (HC) expressing in labor market negatively affects economic growth in some CEMAC member states contradicting our research hypothesis. Possible reasons for this discrepancy could be among others: trainings deliveries don't meet the immediate needs of companies, rather turned to a general education having a technical education link; inadequate school system to the economic needs of the country, a mismatch between the training requested by enterprises and those offered by general and technical education. Therefore, reforming the education system, being in tune with the needs of the countries, is essential. Education must be quality and based on scientific and technical knowledge. Moreover, the retraining of workers in relation to new technologies and literacy of the rural population are essential for a quality workforce.

The trade openness, inflation and country's maritime accessibility have no influence on economic growth observed in the countries of the CEMAC. These results are contrary to the contention that the trade openness increases the welfare of the population. This could be explained by the fact that the economies of these countries are little diversified and that their exports are mainly based on the export of raw materials without added value and the revenue of the exports are insufficient to cover the deficit generated by the imports in the trade balance.

Table 4 : Results of all the estimations

\begin{tabular}{|r|l|l|l|l|l|l|l|l|}
\hline Variables & \multicolumn{2}{|c|}{ OLS } & \multicolumn{2}{c|}{ FEM } & \multicolumn{2}{c|}{ REM } & \multicolumn{2}{c|}{ GMM } \\
\hline GDP & \multicolumn{10}{|c|}{ Coef. } & \multicolumn{1}{|c|}{ P>t } & Coef. & P>t & Coef. & P>z & Coef. & P>z \\
\hline GDP-1 & \multicolumn{7}{|c|}{} \\
\hline FDI & 0.380708 & $0.001^{*}$ & 0.30361 & $0.01 *$ & 0.380708 & $0,000^{*}$ & 0.449476 & $0,000^{*}$ \\
\hline INF & -0.46882 & 0.152 & -0.42019 & 0.172 & -0.46882 & 0.148 & -0.44513 & 0.126 \\
\hline DEBT & -0.06356 & $0.029^{*}$ & 0.0455 & 0.304 & -0.06356 & $0.026^{*}$ & -0.04378 & 0.299 \\
\hline LOAN & -1.41005 & $0.002^{*}$ & -1.98001 & $0,000^{*}$ & -1.41005 & $0.001^{*}$ & -1.66462 & 0,000 \\
\hline TO & -17.4802 & 0.096 & 12.09941 & 0.573 & -17.4802 & 0.092 & -27.095 & 0.122 \\
\hline HC & -0.00488 & 0.974 & 6.013304 & 0.041 & -0.00488 & 0.973 & -0.10734 & 0.752 \\
\hline landlock & -5.97898 & 0.081 & 0 & & -5.97898 & 0.077 & -7.95675 & 0.297 \\
\hline _cons & 24.14639 & 0.095 & -431.616 & 0.048 & 24.14639 & 0.091 & 35.73916 & 0.158 \\
\hline
\end{tabular}

Source : author

\section{Conclusion and Policy Recommendations}

This article is an attempt to identify and point up the main determinants of economic growth in CEMAC in order to enable countries from this sub-regional that assigned themselves targets to achieve on the long term for becoming emerging economies. In this respect, knowing macroeconomic aggregates on which they must rely on to unleash their potential and gain a sustainable economic growth is essential. Ten variables were selected from the literature review, but 2 of the 9 exogenous variables were removed before the modelling.

It appears from the estimation made through panel data modelling and after using specification tests (Fisher, Hausman, Breusch- Pagan and Jarque-Bera tests), the best model in the case of the CEMAC is the fixed effects model. The estimation results bring to the conclusion that two main variables (FDI and LOAN) among seven remaining and used as exogenous variables in the models (MCO, FEM, 
REM and GMM) have a significant impact on economic growth observed in all countries of the CEMAC. If FDI positively contribute to economic growth, LOAN due to bad governance has negative impact and contrast with the assumptions made in the model. Other variables (DEBT and HC) have minor on economic growth in some countries of the CEMAC.

The positive effect of FDI on economic growth in the CEMAC countries is justified by the effectiveness of different policies implemented in these 6 countries to attract foreign investors. It appears necessary for these countries to identify the various factors determining FDI on which action should be taken, wherever possible, to attract more FDI. The econometric analysis does not confirm some findings of the empirical research because the analysis results shows that trade openness, inflation and landlock variables have no influence on economic growth observed in CEMAC. That could be explained by deficiencies that exist in certain political and economic institutions in those countries. Institutions must be strong and credible to ensure the political and macroeconomic stability; they must be able to make good choices of economic policies for strong and sustainable economic growth. Countries must invest more in human capital, especially in technical and scientific fields. Exports must be diversified and not only export raw materials. These countries should focus on manufactured goods having an added value which could bring job creation and generate economic growth necessary to reach the stage of emerging economies.

The landlocked countries, such as Chad and the Central African Republic, don't have outlets to the sea, but it's not an obstacle or a hindrance for the two countries to generate economic growth needed to be an emerging economy.

To conclude from the results of the estimations, if the CEMAC countries want to be part of the group of the emerging economies regarding the targets they set up themselves, they must put in place measures to attract more Foreign Direct Investment, improve governance of public finances and take strong measures to crackdown corruption, promote south-south cooperation to ease the debt burden, improve the training provided by the public and private education so that they are in line with the labor market demand for a good quality workforce. These countries should also add value to the raw materials for export in order to create more jobs, generate more resources improving the welfare of their citizens and break with the current tradition of exporting raw materials without added value.

\section{References}

[1] Alassane D. (2008) "les déterminants de l'épargne nationale : cas du Sénégal», Ecole Nationale Supérieure de Statistique et d'Économie Appliquée (ENSEA), Abidjan, Côte d'Ivoire.

[2] Amadou K. (2010) «Secteur Financier et croissance économique au Niger», Ecole Nationale Supérieure de Statistique et d'Économie Appliquée (ENSEA).

[3] Amadou A. (2006) «libéralisation commerciale et croissance économique dans les pays de

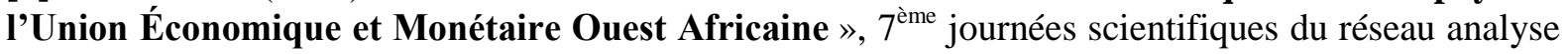
économique et développement de l'AUF.

[4] AKPO K., Yessoufou B. (2009) «Impact des transferts de fonds des migrants sur le développement financier dans les pays de l'Afrique Subsaharienne », Ecole Nationale Supérieure de Statistique et d'Économie Appliquée (ENSEA), Abidjan, Côte d'Ivoire.

[5] Bassanini A., Scarpetta S. (2001) «les moteurs de la croissance dans les pays de l'OCDE : analyse empirique sur des données de panel », Revue économique de l'OCDE n³3.

[6] Cancado L. (2005) « Economic Growth : Panel data evidence from latin America », Center for international studies of Ohio University.

[7] Erginbay U. (2010) « Growth and openness relationship in the EU-15: panel data analysis », Ekonomika Vol. 89(2).

[8] Essissinou A., Kaffo M. (2008) «Analyse de la productivité du capital public dans 48 Etats américains », Ecole Nationale Supérieure de Statistique et d'Économie Appliquée (ENSEA), Abidjan, Côte d'Ivoire. 
[9] George P., Paschalis A., Sotiris P. (2007) « Determinants of Economic Growth: The Experts' View»

[10] Hassen S., Yosra S., Anis S. (2013) «Développement Financier et Croissance Économique : cas de la région MENA », Volume Book : Economics \& Strategic Management of Business Process (ESMB), Vol.2, pp.40-44,2014.

[11] Mamane T. (2012) «Déterminants de la croissance des pays de l'UEMOA : une analyse à l'aide des données de panel », Revue d'Économie théorique et Appliquée, volume 2-Numéro 2, 199 222p.

[12] Mohamed, G. et Seifallah, S. (2012) «Module $\mathbf{n}^{\circ} \mathbf{1}$ : Econométrie des données de panel sous stata », Université de Carthage, 1 ère édition

[13] Noukpo D., Fotie II H., « Les déterminants des investissements directs étrangers en Afrique subsaharienne ", Ecole Nationale Supérieure de Statistique et d'Économie Appliquée (ENSEA), Abidjan, Côte d'Ivoire.

[14] KPODAR K. (2007) «Manuel d'initiation à Stata (version)», Centre d'Etudes et de Recherches sur le Développement International, Clermont-Ferrand, France.

[15] Ouellet E., Belley-Ferris I., Leblond S. (2005) « Guide d'économétrie appliquée pour Stata : ECN 3950 et FAS $3900 »$, Université de Montréal

[16] TRPKOVA M., TASHEVSKA B. (2011) «Determinants of economic growth in South - East Europe: a panel data approach » Perspectives of Innovations, Economics \& Business, Volume 7, Issue 1.

[17] Vescovo A. (2008) « Cours I. Prise en main du logiciel stata », IRD-AFRISTAT. 